\title{
Effect of ageing on magnetic and electrical properties of Ti-substituted La-Sr manganites
}

\author{
A. Badelin ${ }^{1, *}$, Z. Datskaya ${ }^{1}$, S. Estemirova ${ }^{2}$, V. $\operatorname{Karpasyuk}^{1}$, D. Merkulov ${ }^{1}$ \\ ${ }^{1}$ Astrakhan State University, 414056 Astrakhan, Russia \\ ${ }^{2}$ Institute for Metallurgy UB RAS, 620016 Yekaterinburg, Russia
}

\begin{abstract}
The changes of structural, magnetic and electrical parameters of ceramic $\mathrm{La}_{0.8-\mathrm{x}} \mathrm{Sr}_{0.2+\mathrm{x}} \mathrm{Mn}_{1-\mathrm{x}} \mathrm{Ti}_{\mathrm{x}} \mathrm{O}_{3+\gamma}(0.025 \leq \mathrm{x} \leq 0.150)$ manganites during long-term storage at room temperature and after thermal cycling were investigated. The unit cell volume $(\mathrm{V})$ of all manganites decreased over time. Most considerable decrease of $\mathrm{V}$ and broadening of X-ray diffraction lines width were observed in the samples with high quantity of titanium. During the storage period magnetization $(\sigma)$ and Curie point $\left(\mathrm{T}_{\mathrm{c}}\right)$ of manganites with relatively low Ti content decreased, while the compositions with high values of " $\mathrm{x}$ " exhibited some trend of $\sigma$ and $T_{c}$ increase. The resistance of the samples with $\mathrm{x}<0.100$ increased over time. Fluctuations of magnetization of all thermal-aged samples were within the error of measurement, and Curie point of manganites with $\mathrm{x}=0.150$ showed the rise. From the data obtained it might be inferred that ageing phenomena in Ti-substituted manganites can be associated with oxidation processes, the transfer of $\mathrm{Ti}^{4+}$ to vacant sites in rare-earth sublattice and formation of microinhomogeneities.
\end{abstract}

\section{Introduction}

The development of new perspective materials for magnetoelectronics and spintronics, such as ferrites, manganites exhibiting colossal magnetoresistance or manganite electroceramics for thermistors, involves the achieving a number of valuable properties, among which stability of functional parameters in relation to thermal and prolonged storage ageing is of special importance [1-3]. However, the data concerning the ageing processes in bulk ceramic perovskite-like manganites are practically absent in the literature. The long-term stability of resistive and magnetic properties was investigated in nanocompounds $p$ - $\mathrm{La}_{0.8} \mathrm{Mn}_{1.04} \mathrm{O}_{3.5}$ [4] and in nanostructured La-Sr manganite thin films [5]. At the same time, one may specify ferrites $[1,6]$ and manganites with spinel structure for thermistor $[3,7]$ as types of polycrystalline oxide materials in which various effects of ageing have been extensively investigated. Generally, in considered materials the drift of their characteristics during prolonged storage in the absence of thermodynamic equilibrium under specified conditions may be due to various processes: interaction with the oxygen in surrounding atmosphere leading to the changes in the states of variable valency ions and concentration of nonstoichiometry defects; ordering or redistribution of cations and vacancies on the sublattices and in the volume of the crystals; relaxation of elastic stresses or grain boundaries, etc. The introduction of micro-components in the complex non-stoichiometric crystals may have different effects on the solid-state reactions and on exchange of oxygen with the ambient atmosphere depending on the nature of impurities [1,8$10]$.

Here, we present the experimental investigations on the in-time and thermal ageing of Ti-substituted manganites of specifically designed system $\mathrm{La}^{3+}{ }_{0.8-\mathrm{x}} \mathrm{Sr}^{2+}{ }_{0.2+\mathrm{x}} \mathrm{Mn}^{3+}{ }_{0.8-\mathrm{x}-2 \gamma} \mathrm{Mn}^{4+}{ }_{0.2+2 \gamma} \mathrm{Ti}^{4+}{ }_{\mathrm{x}} \mathrm{O}_{3+\gamma}$ $(0.025 \leq \mathrm{x} \leq 0.150), \quad$ in which $\mathrm{Mn}^{4+}$ content is independent of " $\mathrm{x}$ ". These manganites under synthesis conditions in our experiments have excess oxygen content $(\gamma>0)$ [9-11], and after cooling they are not in a state of thermodynamic equilibrium. The transition into energetically more favorable state is a general cause of the ageing processes.

\section{Experimental}

Experimental samples of polycrystalline manganites have been prepared by traditional ceramic techniques in air, including operations of double ground with addition of ethanol, preliminary burning, introduction the binder (aqueous solution of polyvinyl alcohol), pressing the pelletes, final sintering at $1473 \mathrm{~K}$ for $10 \mathrm{~h}$ followed by cooling of the samples in the furnace. Procedures of synthesis are described in more detail in Ref. $[9,11]$.

In-time ageing was studied by periodical determination of the properties of manganites during long-term (up to 33 months) storage of initial samples at room temperature in air. Thermal ageing phenomena were investigated using five cycles "annealing for 6 hours at $573 \mathrm{~K}$-cooling".

$\mathrm{X}$-ray studies were carried out on the diffractometer Shimadzu XRD-7000 in $\mathrm{Cu} K_{\alpha}$ radiation. 
Magnetization per mass unit $(\sigma)$ was measured in magnetic field of $5.6 \mathrm{kOe}$ with accuracy to $1.5-2 \%$. Curie point $\left(\mathrm{T}_{\mathrm{c}}\right)$ was determined as the temperature corresponding to the maximum of $|\mathrm{d} \mu(T) / \mathrm{d} T|$, where $\mu(T)$ is magnetic permeability as a function of temperature. The measurement error depended on the width of ferromagnetic-paramagnetic transition was not more than $5 \mathrm{~K}$.

Measurements of dc electrical characteristics and magnetoresistance $(\mathrm{MR}=(\mathrm{R}(\mathrm{H})-\mathrm{R}(0)) / \mathrm{R}(\mathrm{H}))$ were made using copper contacts sputter-deposited onto opposite planes of pellets (thickness of about $4 \mathrm{~mm}$ ). Magnetic field $(\mathrm{H}=9.2 \mathrm{kOe})$ was parallel to the current direction.

\section{Results and discussion}

All samples were found to be single phased and rhombohedral. The unit cell volume (V) of all manganites decreased over time (Table 1). Most considerable decrease of $\mathrm{V}$ was observed in the samples with high quantity of titanium, which must reduce overstoichiometric oxygen concentration in sintered manganites [9-11].

Table 1. Unit cell volume of manganites in initial state and after 33 months.

\begin{tabular}{|c|c|c|}
\hline \multirow{2}{*}{ Chemical composition } & \multicolumn{2}{|c|}{$\mathrm{V}, \AA^{3}$} \\
\cline { 2 - 3 } & $\begin{array}{c}\text { Initial } \\
\text { samples }\end{array}$ & $\begin{array}{c}\text { Aged } \\
\text { samples }\end{array}$ \\
\hline $\mathrm{La}_{0.750} \mathrm{Sr}_{0.250} \mathrm{Mn}_{0.950} \mathrm{Ti}_{0.050} \mathrm{O}_{3+\gamma}$ & 352.9 & 352.6 \\
\hline $\mathrm{La}_{0.700} \mathrm{Sr}_{0.300} \mathrm{Mn}_{0.900} \mathrm{Ti}_{0.100} \mathrm{O}_{3+\gamma}$ & 353.2 & 352.9 \\
\hline $\mathrm{La}_{0.650} \mathrm{Sr}_{0.350} \mathrm{Mn}_{0.850} \mathrm{Ti}_{0.150} \mathrm{O}_{3+\gamma}$ & 353.5 & 352.9 \\
\hline
\end{tabular}

Variations of diffraction reflexes width during the storage of manganites (Table. 2) were dependent on their composition.

Table 2. Full width (W) at half maximum of diffraction reflexes of $\mathrm{La}_{0.8-\mathrm{x}} \mathrm{Sr}_{0.2+\mathrm{x}} \mathrm{Mn}_{1-\mathrm{x}} \mathrm{Ti}_{\mathrm{x}} \mathrm{O}_{3+\gamma}$ manganites.

\begin{tabular}{|c|c|c|c|c|c|}
\hline \multirow{2}{*}{$\mathrm{x}$} & \multirow{2}{*}{$(\mathrm{HKL})$} & \multicolumn{2}{|c|}{ Initial samples } & \multicolumn{2}{c|}{ After 33 months } \\
\cline { 2 - 6 } & $2 \Theta^{\circ}$ & $\mathrm{W},{ }^{\circ}$ & $2 \Theta,^{\circ}$ & $\mathrm{W},{ }^{\circ}$ \\
\hline \multirow{5}{*}{0.050} & $(10 \overline{\overline{2}})$ & 22.832 & 0.154 & 22.856 & 0.153 \\
\cline { 2 - 6 } & $(110)$ & 32.405 & 0.152 & 32.424 & 0.150 \\
\cline { 2 - 6 } & $(116)$ & 52.743 & 0.170 & 52.763 & 0.166 \\
\cline { 2 - 6 } & $(214)$ & 57.977 & 0.178 & 57.993 & 0.174 \\
\cline { 2 - 6 } & $(208)$ & 68.433 & 0.205 & 68.452 & 0.196 \\
\hline \multirow{5}{*}{0.100} & $(10 \overline{2})$ & 22.828 & 0.191 & 22.846 & 0.187 \\
\cline { 2 - 6 } & $(110)$ & 32.416 & 0.198 & 32.432 & 0.191 \\
\cline { 2 - 6 } & $(116)$ & 52.712 & 0.228 & 52.733 & 0.238 \\
\cline { 2 - 6 } & $(214)$ & 57.975 & 0.238 & 57.996 & 0.252 \\
\cline { 2 - 6 } & $(208)$ & 68.380 & 0.263 & 68.407 & 0.300 \\
\hline \multirow{5}{*}{$0.150 \overline{2})$} & 22.832 & 0.178 & 22.854 & 0.191 \\
\cline { 2 - 6 } & $(110)$ & 32.423 & 0.200 & 32.447 & 0.209 \\
\cline { 2 - 6 } & $(116)$ & 52.689 & 0.258 & 52.716 & 0.278 \\
\cline { 2 - 6 } & $(214)$ & 57.972 & 0.273 & 58.000 & 0.299 \\
\cline { 2 - 6 } & $(208)$ & 68.346 & 0.316 & 68.375 & 0.345 \\
\hline
\end{tabular}

At low titanium content $(\mathrm{x}=0.050)$ all reflexes narrowed over time and at high content $(x=0.150)$ they broadened. At $\mathrm{x}=0.100$ the width of reflexes in the range of small angles decreased and in large angles it increased.

The values of magnetic parameters of manganites measured at certain intervals of time after beginning of the storage are presented on Figure 1. The following values of symbol parameter $\tau$ given on the $\mathrm{x}$-axis of the figure are: $\tau=0$ - start of timing, it fit the parameters of the initial samples; $\tau=1$ means 1 month of storage, $\tau=2$ -7 months, $\tau=3-18$ months, $\tau=4-33$ months.
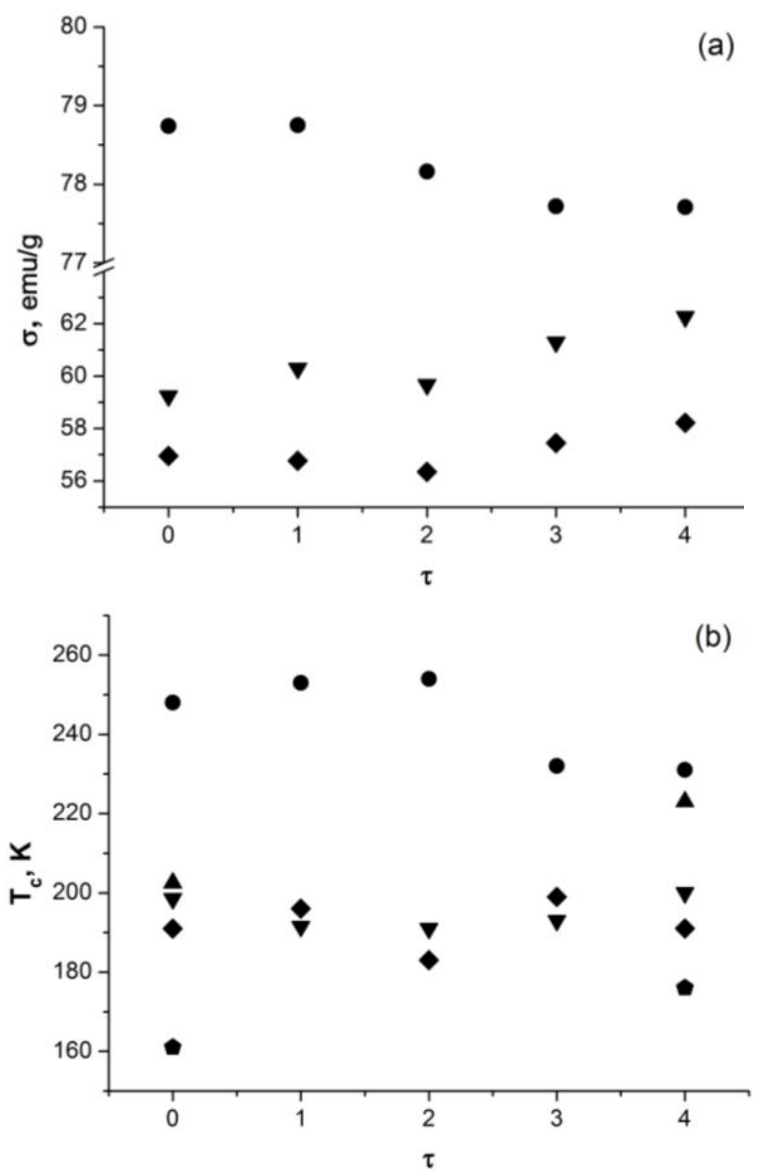

Fig. 1. Magnetization (a) and Curie point (b) of manganites $\mathrm{La}_{0.8-\mathrm{x}} \mathrm{Sr}_{0.2+\mathrm{x}} \mathrm{Mn}_{1-\mathrm{x}} \mathrm{Ti}_{\mathrm{x}} \mathrm{O}_{3+\gamma}$ at different points in storage time: $-x=0.050 ; \boldsymbol{\Delta}-x=0.075 ; \boldsymbol{\nabla}-x=0.100 ;--x=0.125$; $-x=0.150$

As it can be seen from the Figure 1, magnetization and Curie point of manganites with relatively low $\mathrm{Ti}$ content decreased during the storage period, while the compositions with high values of "x" exhibited some trend of $\sigma$ and $T_{c}$ increase. As an example of one conclusion concerning $T_{c}$, temperature dependencies of magnetic permeability of two samples are cited on Figure 2(a).

The resistance of all samples, with the exception of compositions with $x \geq 0.100$, increased during storage period. Figure 2(b) illustrates the qualitatively different changes of the resistance of manganites with $\mathrm{x}=0.025$ and $\mathrm{x}=0.100$. 

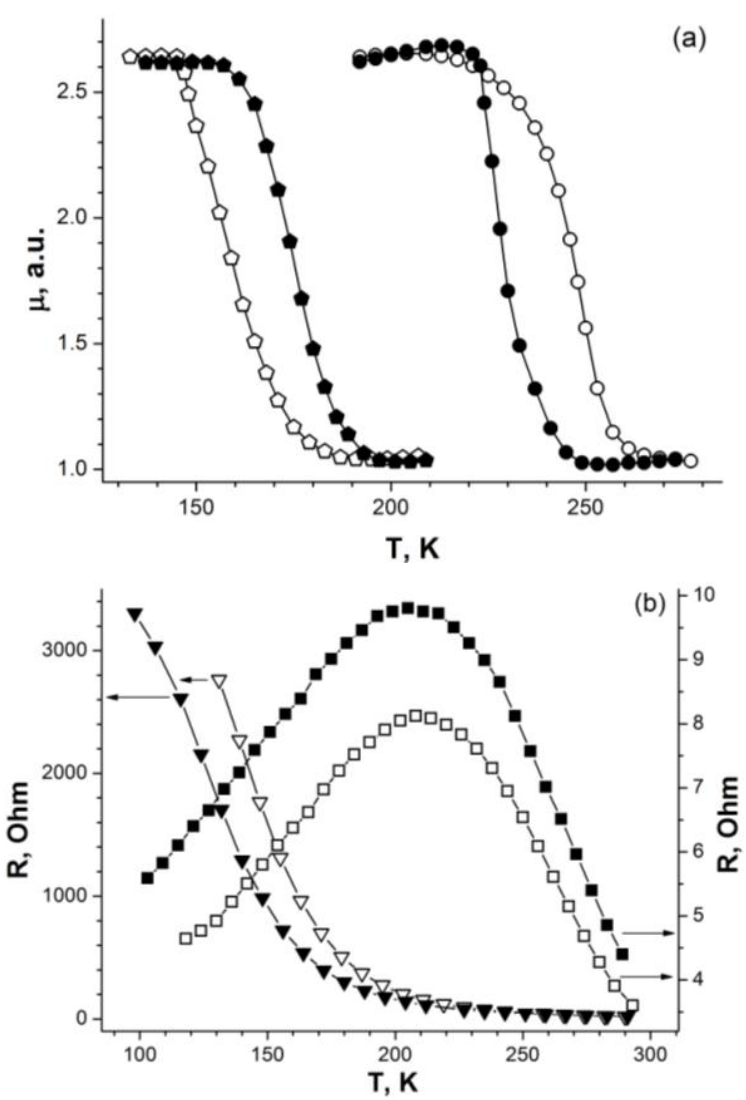

Fig. 2. Temperature dependencies of magnetic permeability (a) and electrical resistance (b) of manganites in initial state (light symbols) and in the end of storage period (black symbols): $(\mathrm{O}, \mathbf{\bullet})-\mathrm{x}=0.050 ;(\triangle, \bullet)-\mathrm{x}=0.150 ;(\square, \square)-\mathrm{x}=0.025$; $(\nabla, \nabla)-\mathrm{x}=0.100$

The curves on Figure 2(b) for $\mathrm{x}=0.025$ demonstrate that in manganite of this composition "metalsemiconductor" transition temperature lowered as a result of in-time ageing.

Magnetoresistance at different temperature intervals changed irregularly during the storage period. Table 3 shows maximumal values of $|\mathrm{MR}|$ and corresponding to them temperatures $\left(\mathrm{T}_{\mathrm{MR}}\right)$ for initial and aged samples.

Table 3. Maximal absolute values of magnetoresistance at corresponding temperatures.

\begin{tabular}{|c|c|c|c|c|}
\hline \multirow{2}{*}{$\mathrm{x}$} & \multicolumn{2}{|c|}{$|\mathrm{MR}|_{\max }, \%$} & \multicolumn{2}{c|}{$\mathrm{T}_{\mathrm{MR}}, \mathrm{K}$} \\
\cline { 2 - 5 } & $\begin{array}{c}\text { Initial } \\
\text { samples }\end{array}$ & $\begin{array}{c}\text { Aged } \\
\text { samples }\end{array}$ & $\begin{array}{c}\text { Initial } \\
\text { samples }\end{array}$ & $\begin{array}{c}\text { Aged } \\
\text { samples }\end{array}$ \\
\hline 0.025 & 14 & 17 & 118 & 130 \\
\hline 0.050 & 13 & 15 & 130 & 96 \\
\hline 0.075 & 20 & 23 & 116 & 100 \\
\hline 0.100 & 35 & 22 & 140 & 111 \\
\hline 0.150 & 36 & 23 & 110 & 105 \\
\hline
\end{tabular}

$\mathrm{T}_{\mathrm{MR}}$ of the majority of the samples decreased during storage time, with the exception of manganite contained 0.025 formula units of Ti. Maximal $|\mathrm{MR}|$ values of manganites with low titanium content did not almost changed, while $|\mathrm{MR}|_{\max }$ of compositions with $\mathrm{x} \geq 0.100$ decreased slightly.
Variations of magnetic characteristics of manganites in the process of frequentative thermal cycling are presented on the Figure $3(a, b)$. One can see that magnetization fluctuations of all samples were within the error of measurement, and manganite with $\mathrm{x}=0.150$ exhibited the rise of Curie point.

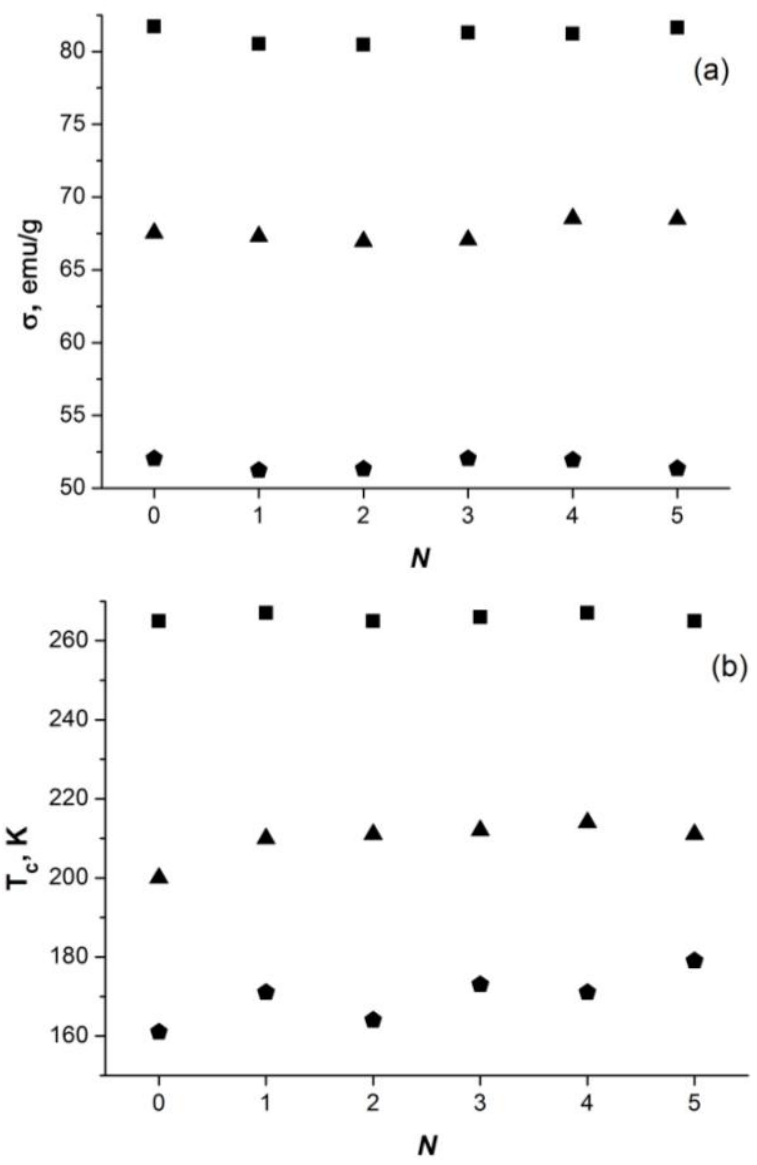

Fig. 3. Magnetization (a) and Curie point (b) of thermal-cycled manganites $\mathrm{La}_{0.8-\mathrm{x}} \mathrm{Sr}_{0.2+\mathrm{x}} \mathrm{Mn}_{1-\mathrm{x}} \mathrm{Ti}_{\mathrm{x}} \mathrm{O}_{3+\gamma}: \mathbf{\square}-x=0.025 ; \boldsymbol{\Delta}$ $x=0.075 ;-x=0.150$; the values of $N$ denote the numbers of cycles $(N=0$ corresponds to the initial sample).

Totality of obtained experimental data seems to agree with following notions.

From the viewpoint of thermodynamics, at the temperature lower than sintering one manganites must absorb the oxygen. Oxidation process causes $\mathrm{Mn}^{3+} \rightarrow \mathrm{Mn}^{4+}$ transition and formation of cation vacancies. As a result, unit cell volume decreases, and concentration of $\left(\mathrm{Mn}^{4+}, \mathrm{Mn}^{3+}\right)$ pairs bonded by double exchange interaction increases, which should lead to higher ferromagnetic characteristics and conductivity. At the same time, the decrease of magnetic moment of the manganese ions and the dilution of octahedral sublattice by cation vacancies are competing factors. Difference of radii and charges of the ions, Coulomb interaction cause the formation of microinhomogeneities and microstresses [8, 9, 12], broadening X-ray diffraction reflexes. At room temperature the contribution of entropy to free energy (-TS term) is less than at thermal processing, and separation of inhomogeneities becomes 
more evident, which can be promoted by the presence of Ti impurity.

Narrowing of diffraction reflexes over time in manganites with low titanium content requires further research.

Another important factor affecting the properties of the manganites is the transfer of $\mathrm{Ti}^{4+}$ to vacant sites in rare-earth sublattice. For this ion, due to the large electric charge, higher coordination may be favorable. The possibility of transition of the cations from octahedral sublattice to sublattice with coordination number of 12 was considered in the works $[13,14]$. As a result of the transfer of $\mathrm{Ti}^{4+}$ ions unit cell volume decreases, diamagnetic dilution of Mn sublattice reduces, double exchange bonds recover, and eventually Curie point and conduction raise.

However, due to the oxidation of copper electrodes by the oxygen from manganites, resistance value of the contact zones may increase.

\section{Conclusion}

Analysis of adduced data permitted establishing the following regularities:

- during the storage period unit cell volume of all samples decreased, magnetization and Curie point of manganites with relatively low Ti content lowered, while the compositions with high values of " $\mathrm{x}$ " exhibited some trend of $\sigma$ and $\mathrm{T}_{\mathrm{c}}$ increase;

- resistance of the samples with $\mathrm{x}<0.100$ increased and with $\mathrm{x} \geq 0.100$ decreased during storage period;

- maximal absolute values of magnetoresistance changed insignificantly in course of time;

- at low titanium content all X-ray reflexes narrowed over time and at high content they broadened;

- in the process of frequentative thermal cycling variations of magnetic characteristics of manganites were within the error of measurement, with the exception of compositions with $\mathrm{x}=0.150$ exhibited the rise of Curie point.

On the whole, it can be concluded that in-time and thermal ageing of manganites leads to the changes of their magnetic parameters within no more than $10 \%$.

Changes in electrical characteristics are more significant, but most likely they are due to oxidation processes in manganite-electrode interface.

Further work will be required to investigate more circumstantially the mechanisms of variations of diffraction reflexes width, electrical characteristics taking into consideration degradation of the contact zones, and to elucidate the role of the changes in microstructure.

This research was supported by the Ministry of Education and Science of RF (project 334).

\section{References}

1. A. Goldman, Modern Ferrite Technology (2 ${ }^{\text {nd }}$ Ed. Pittsburg, PA, USA: Springer, 2006)

2. I.A. Abdel-Latif, J. Phys. 1(3), 15 (2012)
3. M. Vakiv, I. Hadzaman, O. Shpotyuk, O. Mrooz, J. Plewa, H. Altenburg, H. Uphoff, O. Bodak, P. Demchenko, J. Eur. Ceram. Soc. 24, 1277 (2004).

4. A.I. Rykova, A.V. Terekhov, A.S. Cherny, E.N. Khatsko, A.V. Yeremenko, A. Zaleski, Low Temp. Phys. 38(6), 529 (2012).

5. L. Žurauskaitè, S. Balevičius, N. Žurauskienè, S. Keršulis, V. Stankevič, Č. Šimkevičius, J. Novickij, S. Tolvaišienè, Lithuanian J. Phys. 52(3), 224 (2012).

6. S. Krupićka, Physik der ferrite und der verwandten magnetischen oxide (Prag.: Academia, 1973)

7. Dao-lai Fang, Cui-hong Zheng, Chu-sheng Chen, A.J.A. Winnubst, J. Electroceram. 22(4), 421 (2009)

8. Z.R. Musaeva, N.A. Vybornov, V.K. Karpasyuk, A.M. Smirnov, L.S. Uspenskaya, S.Kh. Yazenkov, Journal of Surface Investigation. X-ray, Synchrotron and Neutron Techniques 1(4), 423 (2007)

9. A. Badelin, Z. Datskaya, I. Epifanova, S. Estemirova, V. Karpasyuk, A. Smirnov, Europ. Phys. J. (EPJ Web of Conf.) 40, 15004 (2013)

10. O.Z. Yanchevskii, O.I. V'yunov, A.G. Belous, A.I. Tovstolytkin, V.P. Kravchik, Phys. Sol. State 48(4), 709 (2006)

11. D. Merkulov, A. Badelin, S. Estemirova, V. Karpasyuk, Acta Phys. Pol. A 127(2), 248 (2015)

12. P.G. Radaelli, R.M. Ibberson, D.N. Argyriou, H. Casalta, K.H. Andersen, S.W. Cheong, J.F. Mitchell, Phys. Rev. B 63, 172419 (2001)

13. J. Mizusaki, N. Mori, H. Takai, Y. Yonemura, H. Minamiue, H. Tagawa, M. Dokiya, H. Inaba, K. Naraya, T. Sasamoto, T. Hashimoto, Solid State Ionics 129, 163 (2000)

14. R.A. De Souza, M.S. Islam, E.Ivers-Tiffee, J. Mater. Chem. 9, 1621 (1999) 